\title{
Structural, Photophysical and Chiro-Optical Properties of Lanthanide Complexes with a Bis(benzimidazole)pyridine-Based Chiral Ligand
}

\author{
Gilles Muller, ${ }^{[a, b]}$ Christine L. Maupin, ${ }^{[b]}$ James P. Riehl, ${ }^{[b]}$ Henrik Birkedal, ${ }^{[c, d]}$ \\ Claude Piguet, ${ }^{\text {[e] }}$ and Jean-Claude G. Bünzli* ${ }^{*[a, b]}$
}

Keywords: Lanthanides / Luminescence / Chirality / Complexes / Terdentate ligand

The neutral $\mathrm{Ln}^{\mathrm{III}}$ 1:1 nitrato complexes with the chiral ligand 2,6-bis(1-S-neopentylbenzimidazol-2-yl)pyridine ( $\left.\mathrm{L}^{11}\right)$ have been synthesised and their stability constants measured in acetonitrile $\left(\log K_{1}=4.0-6.4\right)$. The crystal and molecular structure of $\left[\mathrm{Eu}\left(\mathrm{NO}_{3}\right)_{3}\left(\mathrm{~L}^{11}\right)(\mathrm{MeCN})\right]$ shows the typical meridional planar coordination of $\mathrm{L}^{11}$ to the metal ion and low symmetry of the coordination polyhedron. The influence of the steric hindrance generated by the substituent at $\mathrm{R}^{2}$ on the crystal packing and bond lengths is discussed. Photophysical measurements show that ligand $\mathrm{L}^{11}$ induces a ${ }^{3} \pi \pi^{*}$-to-Ln energy-transfer process in the $\mathrm{Eu}^{\mathrm{III}}$ complex, while the $\mathrm{Tb}^{\mathrm{III}}$ compound is ten times less luminescent. Addition of a second molecule of $\mathrm{L}^{11}$ to give $\left[\mathrm{Ln}\left(\mathrm{ClO}_{4}\right)_{2}\left(\mathrm{~L}^{11}\right)_{2}\right]^{+}$leads to a large quenching of the $\mathrm{Eu}^{\mathrm{III}}$ luminescence (140-fold) due to several factors: a less efficient ${ }^{1} \pi \pi^{*} \rightarrow{ }^{3} \pi \pi^{*}$ transfer (ca. fourfold), a smaller intrinsic quantum yield $Q^{\mathrm{Eu}}$ (ca. threefold), and a substantially less efficient ligand-to-metal transfer (ca. 12fold). In the case of the $\mathrm{Tb}^{\mathrm{III}}$ complex, the decrease in the energy of the triplet state reduces further the $\mathrm{Tb}^{\mathrm{III}}$ emission through increased back transfer. The specific rotary dispersion of the 1:1 and 1:2 complexes points to the chirality of the complexes arising mainly from the ligand, while the circularly polarized luminescence of these complexes with $\mathrm{Eu}^{\mathrm{III}}$ and $\mathrm{Tb}^{\mathrm{III}}$ displays a weak effect, pointing to a small diastereomeric excess in solution. Altogether, this study demonstrates that electronic, thermodynamic and photophysical properties of lanthanide complexes with aromatic terdentate ligands can be tuned by modifying the number and the arrangement of the ligands, as well as their substituents, particularly those in the $\mathrm{R}^{2}$ and $\mathrm{R}^{3}$ positions.

(C) Wiley-VCH Verlag GmbH \& Co. KGaA, 69451 Weinheim, Germany, 2003)

\section{Introduction}

Present interest in luminescent lanthanide complexes ${ }^{[1]}$ is primarily motivated by applications in life sciences, mainly for developing chemical sensors ${ }^{[2]}$ or tools for medical diagnosis and therapy ${ }^{[3,4]}$ In this context, the design and use of enantiopure lanthanide compounds present a special advantage with respect to the chiral recognition of biological substrates. ${ }^{[5,6]}$ Lanthanides are subject to fast ligand- and solvent-exchange reactions so that easy interconversion be-

[a] Institute of Molecular and Biological Chemistry, Swiss Federal Institute of Technology, BCH 1402,

$\mathrm{CH}-1015$ Lausanne, Switzerland

E-mail: jean-claude.bunzli@epfl.ch

[b] Department of Chemistry, University of Minnesota Duluth, Duluth, MN, 55812-3020, USA

[c] Institute of Crystallography, BSP, University of Lausanne, CH-1015 Lausanne, Switzerland

[d] Department of Chemistry and Biochemistry, University of California,

Santa Barbara, CA 93106, USA

[e] Department of Inorganic, Analytical and Applied Chemistry, University of Geneva,

30 quai E. Ansermet, CH-1211 Geneva 4, Switzerland

Supporting information for this article is available on the WWW under http://www.eurjic.org or from the author. tween optical isomers often occurs. Therefore, the use of ligands leading to kinetically inert complexes, such as those derived from the dota $(1,4,7,10$-tetraazadodecane $N, N^{\prime}, N^{\prime \prime}, N^{\prime \prime \prime}$,-tetraacetic acid) framework favours the isolation of enantiopure compounds. ${ }^{[7]}$ We have recently reported on the first diastereoselective formation in solution of lanthanide triple helical complexes with a terdentate chiral $C_{2}$-symmetric ligand $\mathbf{L}(-)$ (Scheme 1) derived from terpyridine, as was suggested by their specific rotary dispersion, circularly polarized luminescence (CPL) and NMR spectra. ${ }^{[8]}$ We have also investigated the influence of chiral groups grafted onto aromatic tridentate ligands on the diastereomeric induction in solution. For instance, ligands $\mathbf{L}^{*}$ and $\mathbf{L}^{\mathbf{1 2}}$, with a chiral group in the pyridine 4-position, form thermodynamically stable 1:3 triple helical complexes with $\mathrm{Ln}^{\mathrm{III}}$ ions in acetonitrile, and chiro-optical measurements suggest the helical wrapping of the ligand strands around the $\mathrm{Ln}^{\mathrm{III}}$ ions, while the CPL data are in agreement with a small diastereomeric excess in solution. ${ }^{[9,10]}$

Working along these lines, we have introduced a chiral substituent onto the benzimidazole sidearms of bis(benzimidazole)pyridine to yield $\mathbf{L}^{\mathbf{1 1}}$. However, the bulky neopentyl group precludes the formation of stable triple helical com- 


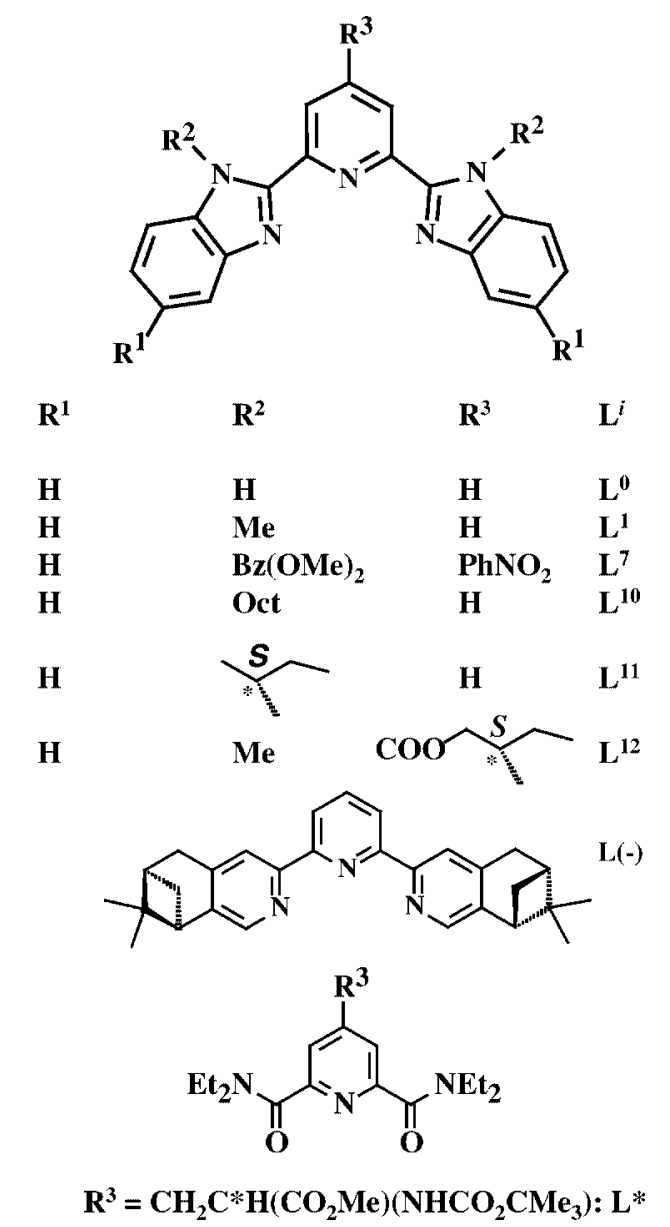

Scheme 1

plexes: in the X-ray structure of $\left[\mathrm{Eu}\left(\mathbf{L}^{\mathbf{1 1}}\right)_{3}\right]\left(\mathrm{ClO}_{4}\right)_{3}$. $4.28 \mathrm{MeCN}$, two of the ligand molecules are wrapped around the $\mathrm{Eu}^{\mathrm{III}}$ ion in a helical fashion, much as they are in the 1:2 complex with $\mathrm{La}^{\mathrm{III}}$, while the third one lies more or less perpendicular to the other two. ${ }^{[1]}$ To further our understanding of the influence of helical wrapping on diastereomeric induction, we investigate here the thermodynamic, structural, luminescent and chiro-optical properties of the neutral nitrato complexes $\left[\mathrm{Ln}\left(\mathrm{NO}_{3}\right)_{3}\left(\mathbf{L}^{\mathbf{1 1}}\right)\right](\mathrm{Ln}=$ $\mathrm{La}, \mathrm{Eu}, \mathrm{Tb}$ ) and compare them to those of [Ln$\left.\left(\mathrm{ClO}_{4}\right)_{2}\left(\mathbf{L}^{\mathbf{1 1}}\right)_{2}\right]^{+}$complexes in solution.

\section{Results and Discussion}

\section{Isolation, Structure and Stability of the 1:1 Nitrato Complexes}

Neutral 1:1 complexes form easily upon mixing equivalent amounts of hydrated lanthanide nitrate and $\mathbf{L}^{\mathbf{1 1}}$ in dichloromethane/acetonitrile. The general formula of the isolated complexes is $\left[\mathrm{Ln}\left(\mathrm{NO}_{3}\right)_{3}\left(\mathbf{L}^{\mathbf{1 1}}\right)(\mathrm{MeCN})_{x}\right][x=0, \mathrm{La}(\mathbf{1})$, Gd (3), Tb (4); $x=1$, Eu (2)] where the acetonitrile molecule sometimes completes the inner-sphere of the $\mathrm{Ln}^{\mathrm{III}}$ ion to a coordination number of 10 (see below), but can be removed by heating under vacuum. Complexation is evi- denced in the IR spectra by the blue shift of the two $\mathrm{C}=\mathrm{C}$ benzimidazole and pyridine vibrational modes by $2-5$ and $11-14 \mathrm{~cm}^{-1}$, respectively (Table S1). Nitrate ions behave as bidentate ligands with local $C_{2 v}$ symmetry as exemplified by energy differences $\Delta\left(v_{1}-v_{4}\right)$ larger than $180 \mathrm{~cm}^{-1,[12]}$ 221, 228, 229, and $230 \mathrm{~cm}^{-1}$ for $\mathrm{La}, \mathrm{Eu}, \mathrm{Gd}$, and $\mathrm{Tb}$, respectively. Single crystals suitable for X-ray diffraction analysis were obtained for the Eu complex 2. The atomnumbering scheme is displayed in Figure 1 and selected bond lengths and angles are reported in Table 1, while interplanar angles are listed in Table S2. The structure consists of neutral molecules with 10-coordinate Eu ${ }^{\mathrm{III}}$, the metal ion being bound to six $\mathrm{O}$ atoms from the three bidentate nitrate anions, one $\mathrm{N}$ atom from the solvating molecule and three $\mathrm{N}$ atoms from $\mathbf{L}^{\mathbf{1 1}}$. The ligand is coordinated in the usual meridional planar way, as was observed for [Eu$\left.\left(\mathrm{NO}_{3}\right)_{3}\left(\mathbf{L}^{\mathbf{1}}\right)(\mathrm{MeOH})\right],{ }^{[13]}$ with two small and very similar interplanar angles between the pyridine and benzimidazole moieties, $\alpha_{\mathrm{pb}}=6.5^{\circ}$ and $6.2^{\circ}$, as compared to $3.3^{\circ}$ and $5.5^{\circ}$ for $\mathbf{L}^{\mathbf{1 1}}$, but in contrast to the situation found in [Eu$\left.\left(\mathrm{NO}_{3}\right)_{3}\left(\mathbf{L}^{\mathbf{7}}\right)(\mathrm{MeCN})\right] \cdot 2.5 \mathrm{MeCN}{ }^{[14]}$ and $\left[\mathrm{Eu}\left(\mathrm{NO}_{3}\right)_{3}\left(\mathbf{L}^{\mathbf{1 0}}\right)\right] \cdot{ }^{[13]}$ Indeed, in the former, $\mathbf{L}^{7}$ is bent with two different angles
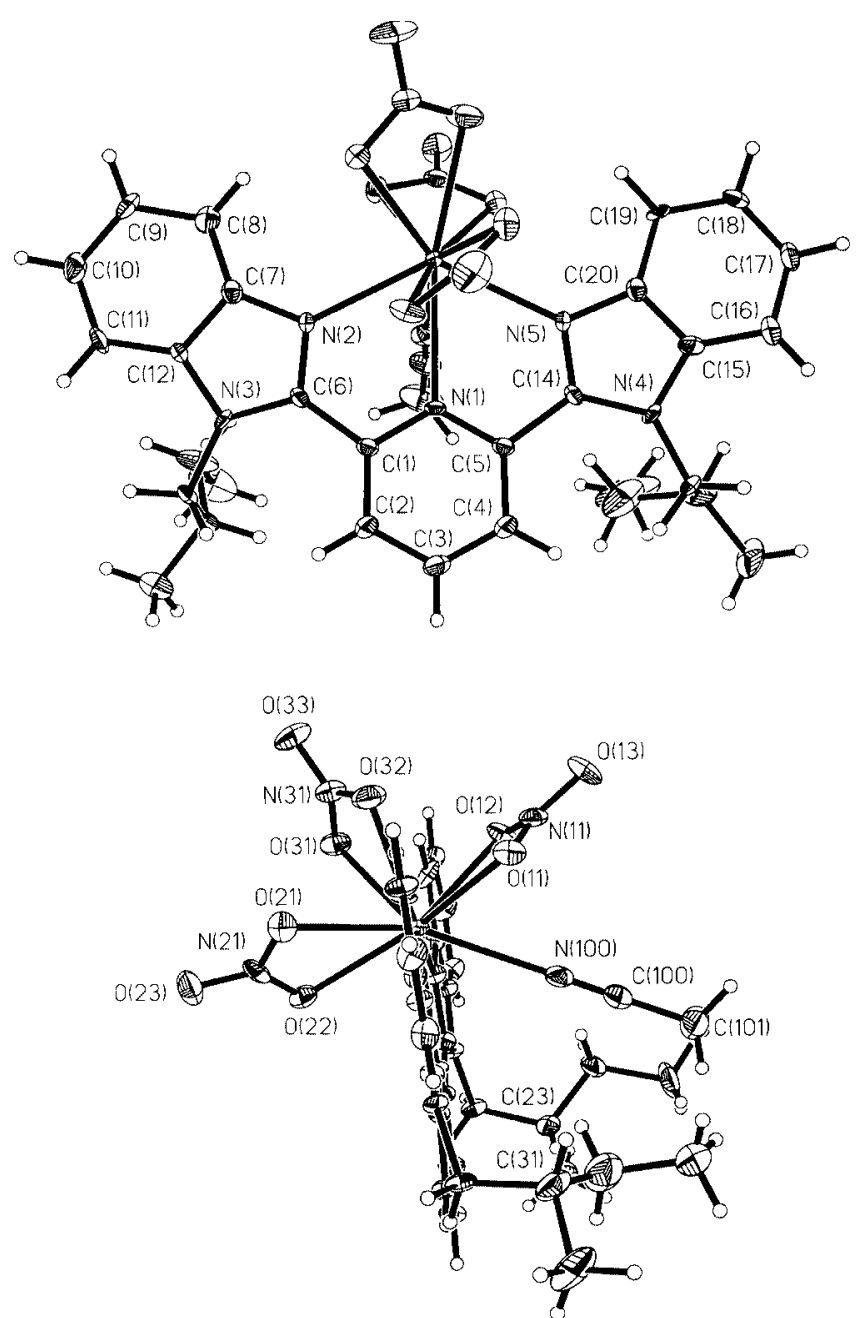

Figure 1. Two views of the molecular structure of $\left[\mathrm{Eu}\left(\mathrm{NO}_{3}\right)_{3}\left(\mathbf{L}^{\mathbf{1 1}}\right)\right.$ $(\mathrm{MeCN})]$ showing the atom-numbering scheme 
Table 1. Bond lengths $(\AA)$ and angles $(\mathrm{deg})$ in the coordination polyhedron of $\left[\mathrm{Eu}\left(\mathrm{NO}_{3}\right)_{3}\left(\mathbf{L}^{\mathbf{1 1}}\right)(\mathrm{MeCN})\right]$

Bond lengths

\begin{tabular}{lllll}
\hline Eu1-N1 & $2.627(4)$ & Eu1-N100 & $2.735(5)$ & Eu1-O21 \\
Eu1-N2 & $2.470(7)$ & Eu1-O11 & $2.486(7)$ & Eu1-O22 \\
Eu1-N5 & $2.470(7)$ & Eu1-O12 & $2.478(7)$ & Eu1-O31 \\
& & & & Eu1-O32 \\
\hline
\end{tabular}

Bond angles

\begin{tabular}{|c|c|c|c|c|c|}
\hline $\mathrm{N} 1-\mathrm{Eu} 1-\mathrm{N} 2$ & $63.8(3)$ & $\mathrm{N} 5-\mathrm{Eu} 1-\mathrm{O} 21$ & $70.8(2)$ & $\mathrm{O} 21-\mathrm{Eu} 1-\mathrm{N} 100$ & $151.7(2)$ \\
\hline $\mathrm{N} 1-\mathrm{Eu} 1-\mathrm{N} 5$ & $63.1(3)$ & $\mathrm{N} 5-\mathrm{Eu} 1-\mathrm{O} 22$ & $88.8(2)$ & $\mathrm{O} 22-\mathrm{Eu} 1-\mathrm{O} 31$ & $71.9(2)$ \\
\hline $\mathrm{N} 2-\mathrm{Eu} 1-\mathrm{N} 5$ & $126.9(1)$ & N5-Eu1-O31 & $139.1(2)$ & $\mathrm{O} 22-\mathrm{Eu} 1-\mathrm{O} 32$ & $104.7(2)$ \\
\hline $\mathrm{N} 1-\mathrm{Eu} 1-\mathrm{O} 11$ & $117.8(2)$ & N5-Eu1-O32 & $103.9(2)$ & O22-Eu1-N100 & 127.1(2) \\
\hline $\mathrm{N} 1-\mathrm{Eu} 1-\mathrm{O} 12$ & $124.8(2)$ & N5-Eu1-N100 & $81.2(3)$ & $\mathrm{O} 31-\mathrm{Eu} 1-\mathrm{O} 32$ & $50.7(2)$ \\
\hline $\mathrm{N} 1-\mathrm{Eu} 1-\mathrm{O} 21$ & $99.6(2)$ & O11-Eu1-O12 & $52.1(2)$ & O31-Eu1-N100 & $139.2(2)$ \\
\hline $\mathrm{N} 1-\mathrm{Eu} 1-\mathrm{O} 22$ & $66.6(2)$ & $\mathrm{O} 11-\mathrm{Eu} 1-\mathrm{O} 21$ & $112.2(2)$ & O32-Eu1-N100 & $128.2(1)$ \\
\hline $\mathrm{N} 1-\mathrm{Eu} 1-\mathrm{O} 31$ & $132.1(2)$ & $\mathrm{O} 11-\mathrm{Eu} 1-\mathrm{O} 22$ & $161.5(2)$ & N1-Eu1-N11 & $125.2(1)$ \\
\hline $\mathrm{N} 1-\mathrm{Eu} 1-\mathrm{O} 32$ & $163.5(2)$ & O11-Eu1-O31 & $109.2(2)$ & N2-Eu1-N11 & 104.9(3) \\
\hline N1-Eu1-N100 & $62.6(1)$ & O11-Eu1-O32 & $66.0(2)$ & N5-Eu1-N11 & $103.6(3)$ \\
\hline $\mathrm{N} 2-\mathrm{Eu} 1-\mathrm{O} 11$ & $126.4(2)$ & O11-Eu1-N100 & $64.7(2)$ & N100-Eu1-N11 & $162.9(1)$ \\
\hline N2-Eu1-O12 & $82.0(2)$ & $\mathrm{O} 12-\mathrm{Eu} 1-\mathrm{O} 21$ & $135.5(2)$ & N31-Eu1-N11 & $79.9(2)$ \\
\hline $\mathrm{N} 2-\mathrm{Eu} 1-\mathrm{O} 21$ & $120.3(2)$ & $\mathrm{O} 12-\mathrm{Eu} 1-\mathrm{O} 22$ & $142.3(2)$ & N1-Eu1-N31 & $153.9(2)$ \\
\hline $\mathrm{N} 2-\mathrm{Eu} 1-\mathrm{O} 22$ & $72.0(2)$ & O12-Eu1-O31 & $77.9(2)$ & N2-Eu1-N31 & $105.9(2)$ \\
\hline $\mathrm{N} 2-\mathrm{Eu} 1-\mathrm{O} 31$ & $81.8(2)$ & O12-Eu1-O32 & $70.9(2)$ & N5-Eu1-N31 & $122.7(2)$ \\
\hline $\mathrm{N} 2-\mathrm{Eu} 1-\mathrm{O} 32$ & $128.5(2)$ & $\mathrm{O} 12-\mathrm{Eu} 1-\mathrm{N} 100$ & $67.0(2)$ & N100-Eu1-N31 & $140.4(1)$ \\
\hline $\mathrm{N} 2-\mathrm{Eu} 1-\mathrm{N} 100$ & $73.5(3)$ & $\mathrm{O} 21-\mathrm{Eu} 1-\mathrm{O} 22$ & $50.1(2)$ & O11-Eu1-N11 & $25.8(3)$ \\
\hline N5-Eu1-O11 & $78.6(2)$ & $\mathrm{O} 21-\mathrm{Eu} 1-\mathrm{O} 31$ & $69.1(2)$ & O21-Eu1-N11 & $127.4(2)$ \\
\hline N5-Eu1-O12 & $128.8(2)$ & $\mathrm{O} 21-\mathrm{Eu} 1-\mathrm{O} 32$ & $65.3(2)$ & O31-Eu1-N11 & $94.0(2)$ \\
\hline
\end{tabular}

$\alpha_{\mathrm{pb}}=4.3^{\circ}$ and $13.1^{\circ}$, while in the latter the two benzimidazole arms of $\mathbf{L}^{\mathbf{1 0}}$ are not coplanar with the central pyridine $\left(\alpha_{\mathrm{pb}}=29.7^{\circ}\right.$ and $\left.28.3^{\circ}\right)$. The observation of different conformations for these ligands may be explained by the crystal packing and the steric hindrance generated by the $\mathrm{R}^{2}$ groups. In $\left[\mathrm{Eu}\left(\mathrm{NO}_{3}\right)_{3}\left(\mathbf{L}^{\mathbf{1 1}}\right)(\mathrm{MeCN})\right]$, the crystal packing is governed by several weak intermolecular $\mathrm{CH} \cdot \cdots \mathrm{O}$ H-bonds, involving the $\mathrm{O}$-atoms of the nitrate anion N2 (Figure 2 and Table S3). Each coordinated $\mathrm{O}$ atom generates one interaction with $\mathrm{H}$ atoms located on the neopentyl arms or on the phenyl groups of another complex molecule, while the noncoordinated $\mathrm{O}$-atom is involved in similar interactions with $\mathrm{H}$ atoms from acetonitrile or from the neopentyl groups of a different complex molecule. The steric hindrance of the

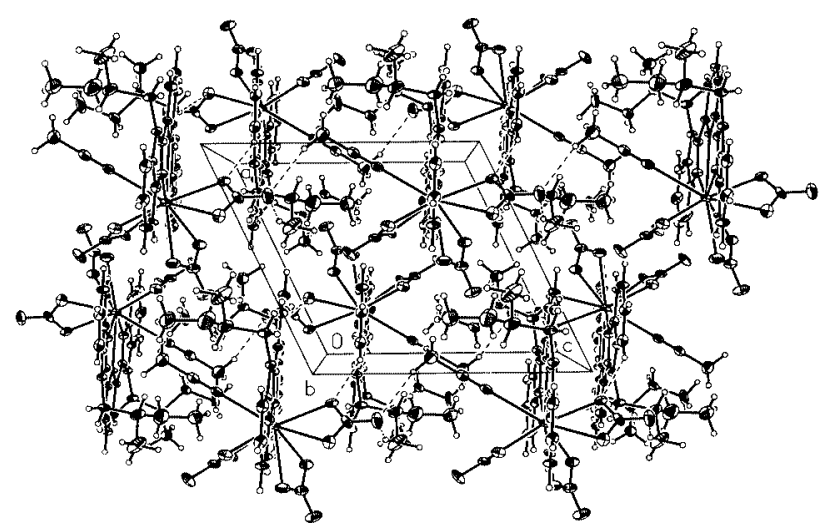

Figure 2. Intermolecular $\mathrm{CH} \cdots \mathrm{O}$ interactions observed in the crystal structure of $\left[\mathrm{Eu}\left(\mathrm{NO}_{3}\right)_{3}\left(\mathbf{L}^{\mathbf{1 1}}\right)(\mathrm{MeCN})\right]$ neopentyl groups increases the bend of the ligand slightly, as previously observed for $\left[\mathrm{Eu}\left(\mathrm{NO}_{3}\right)_{3}\left(\mathbf{L}^{\mathbf{1 0}}\right)\right]$, so that the interstrand $\pi$-stacking interactions evidenced in $\left[\mathrm{Eu}\left(\mathrm{NO}_{3}\right)_{3}\right.$ $\left.\left(\mathbf{L}^{\mathbf{1}}\right)(\mathrm{MeOH})\right]$ are lost. ${ }^{[13]}$ Furthermore, the asymmetric conformation of the two benzimidazole units in $\left[\mathrm{Eu}\left(\mathrm{NO}_{3}\right)_{3}\left(\mathbf{L}^{7}\right)(\mathrm{MeCN})\right] \cdot 2.5 \mathrm{MeCN}$ can be explained by the presence of strong intermolecular interactions, induced by the bulky dimethoxybenzyl substituents, with nitrate anions. $^{[14]}$

The coordination environment of the $\mathrm{Eu}^{\mathrm{III}}$ ion in $\mathbf{2}$ is best described as a distorted 4:5:1 polyhedron (Figure S1) similar to the arrangement observed in the complexes with $\mathbf{L}^{\mathbf{1}}$ [13] and $\mathbf{L}^{7}{ }^{[14]}$ In comparison with $\left[\mathrm{Eu}\left(\mathrm{NO}_{3}\right)_{3}\left(\mathbf{L}^{\mathbf{1}}\right)(\mathrm{MeOH})\right]$, the complexes with $\mathbf{L}^{\mathbf{7}}$ and $\mathbf{L}^{\mathbf{1 1}}$ feature an acetonitrile molecule coordinated to the $\mathrm{Eu}^{\mathrm{III}}$ ion instead of a methanol molecule. This difference does not influence the characteristics of the coordination polyhedron. However, the $\mathrm{Eu}-\mathrm{N}(\mathrm{MeCN})$ distance in $\mathbf{2}(2.735 \AA)$ is substantially longer than those found in the complex with $\mathbf{L}^{7}(2.555 \AA)^{[14]}$ and in the solvate $\left[\mathrm{Sm}(\mathrm{MeCN})_{9}\right]^{3+}(2.54 \AA) .{ }^{[15]}$ This lengthening is a consequence of the acetonitrile molecule in $\mathbf{2}$ being implied in an intermolecular interaction with a nitrate anion (see above). The capping position of the polyhedron is occupied by $\mathrm{N} 2$ from one of the benzimidazole units, while the two planes are defined by $\mathrm{O} 11, \mathrm{O} 21$ and $\mathrm{O} 31$ from the three nitrate anions and N5 from the second benzimidazole substituent, and $\mathrm{O} 12, \mathrm{O} 22$ and $\mathrm{O} 32$ from the nitrates, N1 from the central pyridine, and N100 from the coordinated acetonitrile molecule. The two $\mathrm{Eu}-\mathrm{N}$ (benzimidazole) bonds are symmetric (Table 1), in contrast to the situation 
with $\mathbf{L}^{\mathbf{1}}, \mathbf{L}^{\mathbf{7}}$ and $\mathbf{L}^{\mathbf{1 0}}$ where the two Eu-N(benzimidazole) distances are different, but in all cases shorter than the $\mathrm{Eu}-\mathrm{N}$ (pyridine) bond. On the other hand, we note that the mean $\mathrm{Eu}-\mathrm{N}$ distances in the complexes with $\mathbf{L}^{\mathbf{1 0}}$ and $\mathbf{L}^{\mathbf{1 1}}$ are similar $(2.52 \AA)$ and shorter than in the complexes with ligands bearing small $\mathrm{R}^{2}$ groups such as hydrogen $\{2.58 \AA$, $\left.\left[\mathrm{Eu}\left(\mathrm{NO}_{3}\right)_{2}\left(\mathbf{L}^{\mathbf{0}}\right)_{2}\right]\left(\mathrm{NO}_{3}\right)^{[16]}\right\}$ or methyl $\left(2.54 \AA, \mathbf{L}^{\mathbf{1}}\right) \cdot{ }^{[13]}$ Generally speaking, this mean value decreases with the increase of the steric hindrance generated by the $\mathrm{R}^{2}$ substituents. However, the mean $\mathrm{Eu}-\mathrm{N}$ distance of $2.57 \AA$ in the complex with $\mathbf{L}^{7}$, which contains the bulky dimethoxybenzyl groups, is quite close to the value determined for the complex with $\mathbf{L}^{\mathbf{0}}$, a consequence of the influence of the electronattracting $p$-nitrophenyl group substituted in the $\mathrm{R}^{3}$ position of the central pyridine ring.

All three bidentate nitrate anions bound to the metal ion in 2 have an approximate $C_{2 v}$ local symmetry and present $\mathrm{Eu}-\mathrm{O}$ bonds in the range $2.48-2.59 \AA$, with an average distance of $2.52 \AA$, similar to the values observed in related nitrato complexes $(2.46-2.55 \AA) \cdot{ }^{[13,14,16]}$ The ionic radius calculated according to Shannon's definition $(1.17 \AA)$ is the same as in the other 10-coordinate complexes (1.16$1.17 \AA)^{[13,14,16]}$ and is close to the expected value of 1.18 $\AA .{ }^{[17]}$ Finally, it should be mentioned that the two asymmetric carbon atoms, $\mathrm{C} 21$ and $\mathrm{C} 23$, retain their absolute configuration $S$ in the complex, as was observed in the free ligand. ${ }^{[11]}$

In order to gain information on the stability of the 1:1 nitrato complexes, we performed spectrophotometric and luminescence titrations of $\mathbf{L}^{\mathbf{1 1}}$ with $\mathrm{Ln}\left(\mathrm{NO}_{3}\right)_{3}(\mathrm{Ln}=\mathrm{La}$, $\mathrm{Eu}, \mathrm{Tb}, \mathrm{Lu})$ at $298 \mathrm{~K}$ in $\mathrm{MeCN}$, in the presence of $0.1 \mathrm{M}$ $\mathrm{Et}_{4} \mathrm{NClO}_{4}$, under $\mathrm{N}_{2}$ atmosphere. Factor analysis ${ }^{[18]}$ indicates the presence of two absorbing species and the fit converges for $\log K_{1}=4.0 \pm 0.4,4.0 \pm 0.5,4.0 \pm 0.5$, and 6.4 \pm 0.2 for $\mathrm{La}, \mathrm{Eu}, \mathrm{Tb}$, and $\mathrm{Lu}$, respectively. For $\mathrm{La}$, the stability constant is similar to the value determined for $\mathbf{L}^{\mathbf{1}}$ (4.2 \pm 0.3$){ }^{[19]}$ The $\log K_{1}$ value of the $\mathrm{Eu}^{\mathrm{III}}$ complex determined by luminescence titration is in good agreement with that extracted from the spectrophotometric data: $4.1 \pm 0.4$.

\section{Luminescent Properties of the Nitrato 1:1 and Perchlorato 1:2 Complexes in Solution}

The electronic spectrum of $\mathbf{L}^{\mathbf{1 1}}$ in $\mathrm{MeCN}$ displays one intense band centred at $31385 \mathrm{~cm}^{-1}$, which splits into two components upon complexation, reflecting the electronic transformations associated with the trans-trans $\rightarrow$ cis-cis conformational change and the complexation of the $\mathrm{Ln}^{\mathrm{III}}$ metal to the tridentate binding unit (Table 2). ${ }^{[13,20]} \mathrm{UV}$ irradiation of $\mathbf{L}^{\mathbf{1 1}}$ at room temperature yields one broad unresolved fluorescence band, centred around $27100 \mathrm{~cm}^{-1}$, and originating from the ${ }^{1} \pi \pi^{*}$ state (Figure 3 ). Upon complexation to non-luminescent $\mathrm{Ln}^{\mathrm{III}}$ ions, the energy of the ligand ${ }^{1} \pi \pi^{*}$ state decreases by about 2000 and $2770 \mathrm{~cm}^{-1}$ in the 1:1 and 1:2 complexes, respectively. At $77 \mathrm{~K}$, the ligand triplet state appears at $21120 \mathrm{~cm}^{-1}$ and undergoes a bathochromic shift of $90-185 \mathrm{~cm}^{-1}$ in the nitrato complexes and of $755 \mathrm{~cm}^{-1}$ in the $\mathrm{La}^{\mathrm{III}} 1: 2$ perchlorato complex (Table 2); lifetimes decrease from $389 \pm 4 \mathrm{~ms}$ for the free ligand to $215 \pm 1$ and $93 \pm 5 \mathrm{~ms}$ for the $\mathrm{La} 1: 1$ and $1: 2$ complexes, respectively. In addition to the weak metalcentred emission bands, the luminescence spectra of the $\mathrm{Eu}^{\mathrm{III}}$ and $\mathrm{Tb}^{\mathrm{III}}$ solutions reveal emission from the ligand ${ }^{1} \pi \pi^{*}$ state. The latter is more intense in the case of the $1: 2$ complexes (see Figure 3), for which the ratio between the integrated ligand-centred singlet state and metal-centred emission bands reaches a factor of 280 , compared to about one in the nitrato complexes. The mechanism by which energy is transferred from the ligand to the metal ion involves two essential steps, an intersystem crossing (isc) from the singlet to the triplet state of the ligand and energy transfer to the long-lived excited ${ }^{5} \mathrm{D}_{0}(\mathrm{Eu})$ or ${ }^{5} \mathrm{D}_{4}(\mathrm{~Tb})$ states. ${ }^{[1]}$ To get a better insight into the various energy migration processes occurring in the 1:1 and 1:2 complexes, we determined the quantum yield of both the ligand- and metal-centred luminescence of $10^{-4}$ to $10^{-3} \mathrm{M}$ solutions at $293 \mathrm{~K}$ upon ligand excitation, and the ratio between the integrated triplet and singlet state emissions, $R_{\mathrm{TS}}=I^{\mathrm{T}} / I^{\mathrm{S}}$, for the free ligand and its $\mathrm{La}$ (or $\mathrm{Gd}$ ) complexes at $77 \mathrm{~K}$.

The fluorescence quantum yield of the free ligand, $Q^{\mathrm{F}}=$ $78 \%$, is smaller than for $\mathbf{L}^{1}$, for which it is close to $100 \%$. It is substantially reduced by factors of $55(\mathrm{La})$ and $83(\mathrm{Gd})$ in the 1:1 nitrato complexes, but only by a factor of nine in the perchlorato 1:2 complex with La. Simultaneously, the ligand-centred phosphorescence is enhanced upon complexation as shown by $R_{\mathrm{TS}}$ which increases from $1.5 \times 10^{-4}$ for uncomplexed $\mathbf{L}^{\mathbf{1 1}}$ to $5.5 \times 10^{-3}(\mathrm{La})$ and $1.5 \times 10^{-2}$ $(\mathrm{Gd})$ in the nitrato complexes, and to $1.5 \times 10^{-3}$ in the $\mathrm{La}$ 1:2 complex. The better isc efficiency in 1:1 complexes results (i) from a more favourable energy gap between the ${ }^{1} \pi \pi^{*}$ and ${ }^{3} \pi \pi^{*}$ states: $\Delta E\left({ }^{3} \pi \pi^{*}-{ }^{1} \pi \pi^{*}\right)=4640(\mathrm{La})$ and $4450(\mathrm{Gd}) \mathrm{cm}^{-1}$, as compared to $6660 \mathrm{~cm}^{-1}$ in the free ligand and to $5690 \mathrm{~cm}^{-1}$ in its 1:2 complex with La (ideal value of $5000 \mathrm{~cm}^{-1}$, Figure 4), ${ }^{[21]}$ and (ii) from the mixing of the ligand-centred singlet and triplet wavefunctions promoted by spin-orbit and/or paramagnetic effects. ${ }^{[22]}$

The overall quantum yield of the europium-centred luminescence obtained upon ligand excitation, $Q_{\mathrm{L}}^{\mathrm{Eu}}$, amounts to $1.4 \%$ for the nitrato $1: 1$ complex, as compared to $2.8 \%$ for the corresponding compound with $\mathbf{L}^{\mathbf{1}}{ }^{[19]}$ This quantum yield can be broken down according to the following equation:

$Q_{\mathrm{tot}}^{\mathrm{Eu}}=\eta_{\mathrm{ISC}} \cdot \eta_{\mathrm{ET}} \cdot Q^{\mathrm{Eu}}=\eta_{\mathrm{sens}} \cdot Q^{\mathrm{Eu}}$

where $Q^{\mathrm{Eu}}$ is the intrinsic luminescence quantum yield of the $\mathrm{Eu}^{\mathrm{III}}$ ion, $\eta_{\text {sens }}$ the efficiency of the luminescence sensitisation by the ligand, and $\eta_{\mathrm{ISC}}$ and $\eta_{\mathrm{ET}}$ the yields of the intersystem crossing and of the ligand-to-metal energy transfer, respectively. The intrinsic quantum yield $Q^{\mathrm{Eu}}$ is simply the ratio between the observed and radiative lifetimes of the $\operatorname{Eu}\left({ }^{5} \mathrm{D}_{0}\right)$ level:

$Q^{\mathrm{Eu}}=\tau_{\mathrm{obs}} / \tau_{\mathrm{R}}$

In turn, in the special case of $\mathrm{Eu}^{\mathrm{III}}$, for which the intensity of the magnetic dipole ${ }^{5} \mathrm{D}_{0} \rightarrow{ }^{7} \mathrm{~F}_{1}$ transition is in prin- 
Table 2. Ligand-centred absorptions in acetonitrile, ligand-centred singlet- and triplet-state energies as determined from emission spectra of solutions $10^{-3} \mathrm{M}$ in $\mathrm{MeCN}$ for the ligand $\mathbf{L}^{\mathbf{1 1}}$ and its 1:1 and 1:2 complexes

\begin{tabular}{|c|c|c|c|c|}
\hline Compound & $\begin{array}{l}E\left(x \rightarrow \pi^{*}\right) / \mathrm{cm}^{-1} \\
293 \mathrm{~K}\end{array}$ & $\begin{array}{l}E\left({ }^{1} \pi \pi^{*}\right) / \mathrm{cm}^{-} \\
293 \mathrm{~K} 77 \mathrm{~K}^{[\mathrm{c}]}\end{array}$ & & $\begin{array}{l}E\left({ }^{3} \pi \pi^{*}\right) / \mathrm{cm}^{-1} \\
77 \mathrm{~K}^{[\mathrm{c}]}\end{array}$ \\
\hline \multirow[t]{3}{*}{$\mathrm{L}^{11}$} & $31385(4.48)$ & & & 21120 \\
\hline & & & 27780 & 19685 \\
\hline & & 27100 & 26810 & 18780 \\
\hline \multirow[t]{3}{*}[\mathrm{La}(\mathrm{NO}_{3})_{3}(\mathbf{L}^{11})]{} & $31950(4.44)$ & & & 20935 \\
\hline & $30120(4.44)$ & $27250 \mathrm{sh}$ & 25575 & 19640 \\
\hline & & 25250 & 24750 & 18360 \\
\hline \multirow[t]{2}{*}[\mathrm{Eu}(\mathrm{NO}_{3})_{3}(\mathbf{L}^{\mathbf{11}})(\mathrm{MeCN})]{} & $32465(4.41)$ & 26845 & [d] & [e] \\
\hline & $28925(4.46)$ & 25445 & & \\
\hline \multirow[t]{3}{*}[\mathrm{Gd}(\mathrm{NO}_{3})_{3}(\mathbf{L}^{\mathbf{11}})]{} & $32260(4.41)$ & & & 21030 \\
\hline & $28820(4.46)$ & $27360 \mathrm{sh}$ & 25480 & 19630 \\
\hline & & 25000 & 24600 & 18315 \\
\hline \multirow[t]{2}{*}[\mathrm{Tb}(\mathrm{NO}_{3})_{3}(\mathbf{L}^{\mathbf{11}})]{} & $32465(4.44)$ & & [d] & [e] \\
\hline & $28820(4.44)$ & 24785 & & \\
\hline \multirow{3}{*}[\mathrm{La}(\mathrm{ClO}_{4})_{2}(\mathbf{L}^{\mathbf{11}})_{2}]{$^{+}$} & $32050(4.69)$ & & 26055 & \\
\hline & $29585(4.71)$ & & 24845 & 20365 \\
\hline & & 24330 & 23895 & 18330 \\
\hline \multirow[t]{2}{*}[\mathrm{Eu}(\mathrm{ClO}_{4})_{2}(\mathbf{L}^{\mathbf{11}})_{2}]{$^{+}$} & $32585(4.60)$ & $26845 \mathrm{sh}$ & [d] & [e] \\
\hline & $28530(4.57)$ & 23875 & & \\
\hline$\left[\mathrm{Tb}\left(\mathrm{ClO}_{4}\right)_{2}\left(\mathbf{L}^{\mathbf{1 1}}\right)_{2}\right]^{+}$ & $32580(4.69)$ & & [d] & [e] \\
\hline
\end{tabular}

${ }^{[a]} \mathrm{sh}=$ shoulder; at the concentration used, about 97 , and $72-77 \%$ of the metal ion is under the form of the 1:2 and $1: 1$ complexes and 3 , and $23-28 \%$ under the form of the $1: 1$ complex and free ligand in 1:2 and 1:1 solutions, respectively. ${ }^{[\mathrm{b}]} x=\mathrm{n}$ or $\pi$; Log $\varepsilon$ values are given between parentheses. ${ }^{[c]}$ The 0 -phonon transition is given in italics for frozen solutions in MeCN. ${ }^{[\mathrm{d}]}$ Not measured. ${ }^{[\mathrm{e}]}$ Not observed because of the L11-to-Ln energy transfer process.

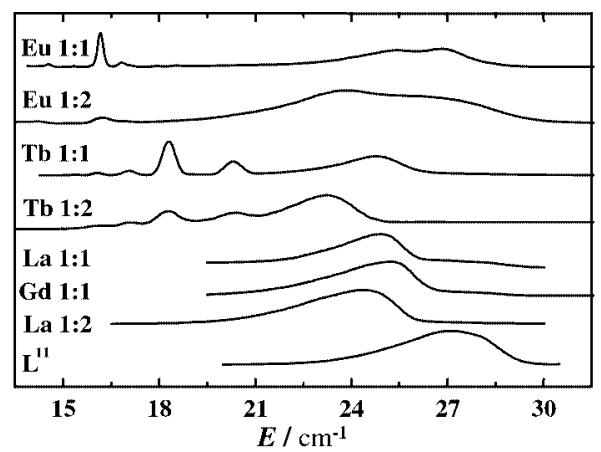

Figure 3. Emission spectra of $\left[\mathrm{Ln}\left(\mathrm{NO}_{3}\right)_{3}\left(\mathbf{L}^{\mathbf{1 1}}\right)(\mathrm{MeCN})_{x}\right](x=0,1)$, $\left[\mathrm{Ln}\left(\mathrm{ClO}_{4}\right)_{2}\left(\mathbf{L}^{11}\right)_{2}\right]^{+}$, and $\mathbf{L}^{\mathbf{1 1}} 10^{-3} \mathbf{M}$ in $\mathrm{MeCN}$ at $293 \mathrm{~K}$

ciple independent of the chemical environment, the radiative lifetime $\tau_{R}$ can be estimated from: ${ }^{[23]}$

$\tau_{\mathrm{R}}=\left[1 /\left(\mathrm{A}_{\mathrm{MD}, 0} \cdot n^{3}\right)\right] \cdot\left(I_{\mathrm{MD}} / I_{\mathrm{tot}}\right)$

in which $\mathrm{A}_{\mathrm{MD}, 0}$ is the spontaneous emission probability of the $\operatorname{Eu}\left({ }^{5} \mathrm{D}_{0} \rightarrow{ }^{7} \mathrm{~F}_{1}\right)$ transition $\left(14.65 \mathrm{~s}^{-1}\right), n$ is the refractive index (1.34 for the acetonitrile solution) and $I_{\mathrm{MD}} / I_{\text {tot }}$ is the intensity ratio of the $\operatorname{Eu}\left({ }^{5} \mathrm{D}_{0} \rightarrow{ }^{7} \mathrm{~F}_{1}\right)$ transition to the total emission of the ${ }^{5} \mathrm{D}_{0}$ level. For the $1: 1$ complex, $I_{\mathrm{MD}} /$ $I_{\text {tot }}=0.1$, leading to $\tau_{\mathrm{R}}=2.8 \mathrm{~ms}, Q^{\mathrm{Eu}}=0.47\left(\tau_{\mathrm{obs}}=1.32\right.$ $\pm 0.01 \mathrm{~ms}$ ) and $\eta_{\text {sens }}=0.03$. The isc efficiency in $\left[\mathrm{La}\left(\mathrm{NO}_{3}\right)_{3} \mathbf{L}^{\mathbf{1 1}}\right]$ is about three times larger than in the nitrato La complex with $\mathbf{L}^{\mathbf{1}}$. Since the energy gaps $\Delta E\left({ }^{3} \pi \pi^{*}{ }_{-}^{5} \mathrm{D}_{0}\right)$ are comparable - ca. $3600 \mathrm{~cm}^{-1}$ and $3700 \mathrm{~cm}^{-1}$ for the complexes with $\mathbf{L}^{\mathbf{1}}$ and $\mathbf{L}^{\mathbf{1 1}}$, respectively, as estimated from $E\left({ }^{3} \pi \pi^{*}\right)$ in the La complexes - the smaller overall quantum
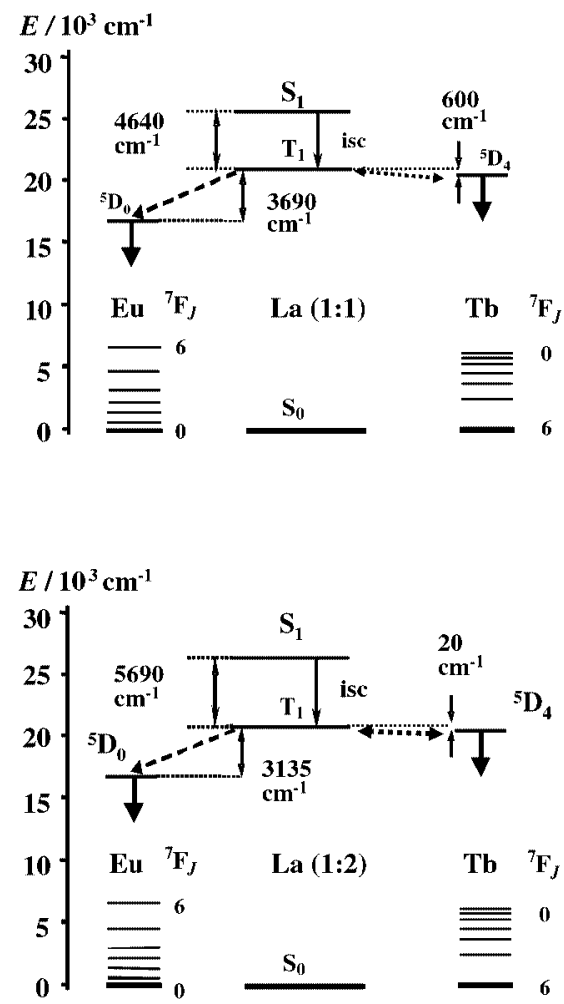

Figure 4. Schematic energy diagram for $\left[\mathrm{Ln}\left(\mathrm{NO}_{3}\right)_{3}\left(\mathbf{L}^{\mathbf{1 1}}\right)(\mathrm{MeCN})_{x}\right]$ $(x=0,1)$ and $\left[\mathrm{Ln}\left(\mathrm{ClO}_{4}\right)_{2}\left(\mathbf{L}^{11}\right)_{2}\right]^{+}$complexes; data for $\mathrm{S}_{1}$ and $\mathrm{T}_{1}$ are those of the LaII complexes in frozen solution at $77 \mathrm{~K}(0$ phonon transitions) 
yield of $\left[\mathrm{Eu}\left(\mathrm{NO}_{3}\right)_{3} \mathbf{L}^{11}\right]$ compared with the $\mathbf{L}^{\mathbf{1}}$ complex can be traced back to more efficient non-radiative deactivation processes taking place in the former complex, probably in view of the larger fluxionality induced by the neopentyl substituents.

The situation is different in the $\mathrm{Eu}$ 1:2 complexes with $\mathbf{L}^{\mathbf{1 1}}$ for which the quantum yield drops to $1 \times 10^{-2} \%$. With respect to the nitrato $1: 1$ complex, the $\Delta\left({ }^{3} \pi \pi^{*}-{ }^{5} \mathrm{D}_{0}\right)$ gap decreases from ca. $3700 \mathrm{~cm}^{-1}$ to ca. $3100 \mathrm{~cm}^{-1}$, which should be more favourable for the sensitisation of the metal luminescence. On the other hand, the isc process is about four times less efficient (compare the $R_{\mathrm{TS}}$ values given above for the La complexes) and the intrinsic quantum yield is smaller: a calculation similar to the one above leads to $I_{\mathrm{MD}} /$ $I_{\text {tot }}=0.18, \tau_{\mathrm{R}}=5.1 \mathrm{~ms}, Q^{\mathrm{Eu}}=0.14\left(\tau_{\mathrm{obs}}=0.73 \pm 0.01\right.$ $\mathrm{ms})$. Consequently, $\eta_{\text {sens }}=7 \times 10^{-4}$, that is 42 -fold smaller than in the 1:1 complex. Therefore, the 140-fold drop in the overall quantum yield of the 1:2 complex compared with the $1: 1$ compound can be roughly broken into three contributions: a less-efficient ${ }^{1} \pi \pi^{*} \rightarrow{ }^{3} \pi \pi^{*}$ transfer (ca. fourfold), a smaller intrinsic quantum yield $Q^{\mathrm{Eu}}$ (ca. threefold), and a substantially less efficient ligand-to-metal transfer (ca. 12fold). A similar, but much more dramatic decrease in the overall quantum yield (3400-fold) has been reported for $\left[\mathrm{Eu}\left(\mathbf{L}^{\mathbf{1}}\right)_{3}\right]^{3+}$ compared with $\left[\mathrm{Eu}\left(\mathrm{NO}_{3}\right)_{3}\left(\mathbf{L}^{\mathbf{1}}\right)(\mathrm{MeOH})\right]$. This effect was assigned, both on the basis of experimental data $^{[19]}$ and theoretical modelling, ${ }^{[24]}$ to the presence of a ligand-to-metal charge transfer (LMCT) state with an energy close to that of the ligand singlet state.

$\mathrm{The} \mathrm{Tb}^{\mathrm{III}}$ complexes are about ten times less luminescent than the $\mathrm{Eu}^{\mathrm{III}}$ analogues, with $Q_{\mathrm{L}}^{\mathrm{Tb}}=1.1 \times 10^{-1}$ and 1.3 $\times 10^{-3} \%$ for the $1: 1$ and $1: 2$ complexes, respectively. The main reason is a deactivation through energy back-transfer onto the ligand since the energy gap $\Delta\left({ }^{3} \pi \pi^{*}-{ }^{5} D_{4}\right)$ amounts to only 600 and $20 \mathrm{~cm}^{-1}$, respectively. The more efficient back-transfer taking place in the 1:2 complex compared with the nitrato compound is exemplified by the temperature dependence of the ${ }^{5} \mathrm{D}_{4}(\mathrm{~Tb})$ lifetimes, which are longer, for solid state samples, than for the nitrato complex. ${ }^{[25]}$

\section{Chiro-Optical Properties}

The specific rotary dispersion of solutions of the $\left[\mathrm{Ln}\left(\mathrm{NO}_{3}\right)_{3}\left(\mathbf{L}^{\mathbf{1 1}}\right)(\mathrm{MeCN})_{x}\right](x=0,1)$ complexes $\left(10^{-3} \mathrm{M}\right.$ in anhydrous acetonitrile) amounts to $18.8 \pm 0.8(\mathrm{La}), 17.1 \pm$ $0.2(\mathrm{Eu}), 16.8 \pm 0.3(\mathrm{Gd})$ and $19.1 \pm 0.3(\mathrm{~Tb})$ deg $\cdot \mathrm{dm}^{2} \cdot \mathrm{mol}^{-1}$. These values are close to the one measured for the free ligand $\left(15.1 \pm 0.3 \mathrm{deg} \mathrm{dm} \mathrm{dmol}^{-1}\right)$, pointing essentially to no structural contribution to the chiro-optical effect. For the 1:2 complexes, a similarly small structural contribution (4-5 deg $\mathrm{dm}^{2} \mathrm{~mol}^{-1}$ ) has been evidenced. ${ }^{[1]}$ As a comparison, 4- to 10-fold larger rotary dispersion values have been observed for 1:3 complexes with ligands $\mathbf{L}^{12[10]}$ and $\mathbf{L}^{*[9]}$ compared with the free ligand value, pointing to the importance of the structural contribution in triple-stranded chiral helical complexes.

We have resorted to circularly polarized luminescence (CPL) to determine whether or not the 1:3 complex with
$\mathbf{L}^{\mathbf{1 1}}$ presents an enantiomeric excess of one isomer. CPL spectra were measured for solutions of $\left[\mathrm{Eu}\left(\mathrm{NO}_{3}\right)_{3}\left(\mathbf{L}^{\mathbf{1 1}}\right)\right.$ $(\mathrm{MeCN})],\left[\mathrm{Ln}\left(\mathrm{ClO}_{4}\right)_{2}\left(\mathbf{L}^{\mathbf{1 1}}\right)_{2}\right]^{+}(\mathrm{Ln}=\mathrm{Eu}, \mathrm{Tb}) 1-1.6 \times 10^{-3}$ $\mathrm{M}$ and for a perchlorate solution containing an Eu: $\mathbf{L}^{\mathbf{1 1}}$ ratio equal to 1:34. In the latter, high resolution luminescence spectra (in a mixture of anhydrous $\mathrm{MeCN}: \mathrm{CH}_{2} \mathrm{Cl}_{2}, 97: 3$ ) show that the 1:3 species exists in a proportion of about $20 \%$ (Figure S2), the remaining Eu-containing species being the $1: 2$ complex, while only $1 \%$ of the $\mathrm{Eu}^{\mathrm{III}}$ ions are in the $1: 3$ form in a $10^{-3} \mathrm{M}$ perchlorate solution with a stoichiometric 1:3 ratio. The excitation spectrum of $\left[\mathrm{Eu}\left(\mathrm{ClO}_{4}\right)_{2}\left(\mathbf{L}^{11}\right)_{2}\right]^{+} 10^{-3} \mathrm{M}$ in the range of the ${ }^{5} \mathrm{D}_{0} \leftarrow{ }^{7} \mathrm{~F}_{0}$ transition reveals the presence of two bands at 17260 and $17244 \mathrm{~cm}^{-1}$ originating from the 1:1 and $1: 2$ complexes, respectively (Figure $\mathrm{S} 3$ ). The presence of the 1:1 species in the $10^{-3} \mathrm{M}\left[\mathrm{Eu}\left(\mathrm{ClO}_{4}\right)_{2}\left(\mathbf{L}^{\mathbf{1 1}}\right)_{2}\right]^{+}$solution is confirmed by the speciation that can be calculated from the stability constants: ${ }^{[11]}$ a $10^{-3} \mathrm{M}$ solution contains $97 \%$ of the $1: 2$ species and about $3 \%$ of the $1: 1$ species. However, the quantum yield of the latter is 140 times larger than for the 1:2 compound, which explains the observation of both species in the excitation spectrum with similar intensity.

The emission of the magnetic dipolar ${ }^{5} \mathrm{D}_{0} \rightarrow{ }^{7} \mathrm{~F}_{1}$ transition is circularly polarized for the three $\mathrm{Eu}^{\mathrm{III}}$ solutions with very small $\Delta I$ values, the smallest effect occurring, as expected, for the 1:1 species (Figure 5). We interpret these data as follows. The CPL properties observed for $\left[\mathrm{Eu}\left(\mathrm{NO}_{3}\right)_{3}\left(\mathbf{L}^{11}\right)\right.$ $(\mathrm{MeCN})$ ] result solely from the effect of the chirality of the ligand, while for the 1:2 and 1:3 compounds, the structural contribution of the helical wrapping of the ligands also contributes to $\Delta I$. It is noteworthy that for the solutions of the perchlorato complexes, $\Delta I$ depends on the polarisation of the excitation light, indicating the presence of more than a single species in solution. ${ }^{[26]}$ The CPL spectrum of the corresponding terbium 1:2 perchlorato complex displays a low $\Delta I$ value (Figure $\mathrm{S} 4$ ), which also demonstrates that the compound is not a racemic mixture in solution. Therefore, the chiro-optical data presented here are consistent with the presence of small diastereomeric excesses in solutions of the $1: 2$ and 1:3 complexes, on the short time scale of optical

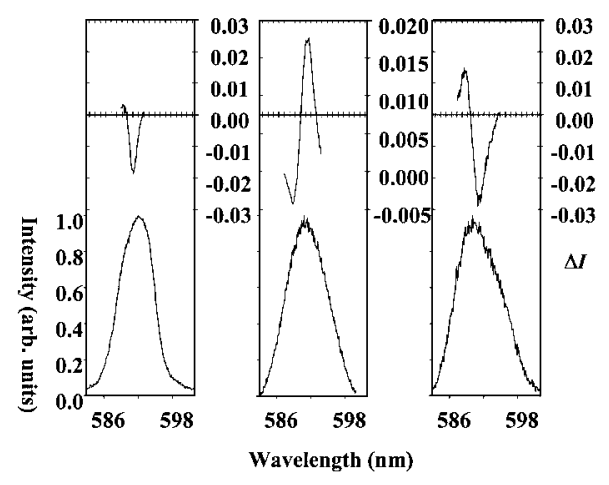

Figure 5. CPL spectrum of the ${ }^{5} \mathrm{D}_{0} \rightarrow{ }^{7} \mathrm{~F}_{1}$ transition of $1-1.6 \times$ $10^{-3}$ M solutions of $\left[\mathrm{Eu}\left(\mathrm{NO}_{3}\right)_{3}\left(\mathrm{~L}^{11}\right)(\mathrm{MeCN})\right]$ (left), $\left[\mathrm{Eu}\left(\mathrm{ClO}_{4}\right)_{2}-\right.$ $\left.\left(\mathbf{L}^{11}\right)_{2}\right]^{+}$(middle) in anhydrous MeCN and one with an Eu: $\mathbf{L}^{11}$ ratio of 1:34 (right) in a mixture of anhydrous $\mathrm{MeCN}$ and $\mathrm{CH}_{2} \mathrm{Cl}_{2}(97: 3)$ at $293 \mathrm{~K}$ 
measurements, as previously observed for 1:3 complexes with $\mathbf{L}^{\mathbf{1 2}}{ }^{[10]}$ and $\mathbf{L}^{*}{ }^{[9]}$

\section{Conclusion}

The structural properties of $\left[\mathrm{Eu}\left(\mathrm{NO}_{3}\right)_{3}\left(\mathbf{L}^{\mathbf{1 1}}\right)(\mathrm{MeCN})\right]$ are similar to those of the $\mathrm{Eu}^{\mathrm{III}}$ complexes with ligands $\mathbf{L}^{\mathbf{1}}$ and $\mathbf{L}^{7}$. Upon complexation, the ligand adopts a cis-cis configuration which implies a meridional planar coordination of the $\mathrm{Eu}^{\mathrm{III}}$ metal. The introduction of various substituents in the $\mathrm{R}^{2}$ position influences both the inner coordination sphere of the metal ion and the crystal packing, which is mainly governed by intermolecular interactions involving hydrogen bonds. The addition of a second ligand in the perchlorato 1:2 complexes significantly modifies the photophysical properties. For $\mathrm{Eu}^{\mathrm{III}}$, an efficient quenching of the metal-centred luminescence occurs which is due to several factors, one of which could be lowering of the energy of the LMCT state. Ligand $\mathbf{L}^{\mathbf{1 1}}$ is not a good sensitizer of the $\mathrm{Tb}^{\mathrm{III}}$ luminescence in view of its too low-lying triplet state, and the introduction of a second ligand molecule lowers the energy of this state still further, leading to increased energy back-transfer. This study confirms that electronic, thermodynamic and photophysical properties of lanthanide complexes with aromatic terdentate ligands can be tuned by modifying the number, the arrangement and the nature of the ligands. In particular, the nature of electron-attracting or -withdrawing $\mathrm{R}^{2}$ or $\mathrm{R}^{3}$ groups influences critically the physicochemical properties of the complexes. Contrary to what was observed for the tris complexes with $\mathbf{L}^{12},{ }^{[10]} \mathbf{L}^{*}{ }^{\text {[9] }}$ and $\mathbf{L}(-),{ }^{[8]}$ the chiro-optical properties of the $1: 2$ and $1: 3$ complexes mainly arise from the chirality of the ligand and not from a structural contribution due to the helical wrapping of the ligand strands around the $\mathrm{Ln}^{\mathrm{III}}$ ions. On the other hand, small enantiomeric excesses are generated in solutions of $1: 2$ and 1:3 complexes.

\section{Experimental Section}

Solvents and Starting Materials: Acetonitrile and dichloromethane were distilled from $\mathrm{CaH}_{2}$. Other products were purchased from Fluka AG (Buchs, Switzerland) or Merck and used without further purification. The ligand $\mathbf{L}^{\mathbf{1 1}}$, its 1:2 complexes and lanthanide perchlorates and nitrates were synthesised as described previously. ${ }^{[11,27]}$

Caution: Dry perchlorates and their complexes with aromatic amines may easily explode and should be handled in small quantities and with extreme precaution. ${ }^{[28]}$

Spectroscopic and Analytical Measurements: Electronic spectra in the UV/Vis range were recorded at $293 \mathrm{~K}$ with a Perkin-Elmer Lambda 900 spectrometer using 1.0 and $0.1 \mathrm{~cm}$ quartz cells. Specific rotary dispersion values were measured from $10^{-3} \mathrm{M}$ solutions in degassed anhydrous acetonitrile at $298 \mathrm{~K}$ with the help of a JASCO DIP-370 polarimeter (sodium D line). IR spectra were obtained from $\mathrm{KBr}$ pellets with a Mattson $\alpha$-Centauri FT-IR spectrometer. Ligand excitation and emission spectra were recorded on a Perkin-Elmer LS-50B spectrometer equipped for low temperature $(77 \mathrm{~K})$ measurements. The experimental procedures for high resolution, laser excited luminescence studies have been published previously. ${ }^{[29]}$ Emission spectra are corrected for the instrument function. Quantum yields of the ligand-centred emission were measured relative to quinine sulfate in $0.05 \mathrm{M} \mathrm{H}_{2} \mathrm{SO}_{4}\left(A_{347}=0.05\right.$, absolute quantum yield: 0.546). ${ }^{[30]}$ Quantum yields of the metalcentred emission were determined as described previously ${ }^{[19]}$ at excitation wavelengths at which (i) the Lambert-Beer law is obeyed, and (ii) the absorption of the reference $\left[\operatorname{Ln}(\text { terpy })_{3}\right]^{3+}$ closely matches that of the sample. CPL measurements were made on an instrument described previously, operating in a differential photoncounting mode. ${ }^{[26]}$ Elemental analyses were performed by Dr H. Eder (Microchemical Laboratory, University of Geneva).

Spectrophotometric Titrations: The electronic spectra in the UV/ Visible range were recorded at $298 \mathrm{~K}$ from $10^{-4} \mathrm{M}$ solutions in acetonitrile containing $\mathrm{Et}_{4} \mathrm{NClO}_{4} 0.1 \mathrm{M}$ as inert electrolyte with a Perkin-Elmer Lambda 7 spectrometer connected to an external personal computer and using quartz cells of $0.100 \mathrm{~cm}$ path length. Solutions were prepared in a thermostatted vessel (Metrohm 6.1418.220) and the titrating solution was added with an automated burette from Metrohm (6.1569.150 or -.210) fitted with an antidiffusion device. In a typical experiment, $5-10 \mathrm{~cm}^{3}$ of $\mathbf{L}^{\mathbf{1 1}}$ were titrated with a solution of $\mathrm{Ln}^{\mathrm{III}}$ nitrate $10^{-4} \mathrm{M}$ in acetonitrile, under $\mathrm{N}_{2}$ atmosphere. After each addition of $0.10 \mathrm{~cm}^{3}$ and a delay of $2 \mathrm{~min}$, the spectrum was measured and transferred to the computer. Factor analysis and stability constant determinations were carried out with the program SPECFIT, version $2.10( \pm 2 \sigma){ }^{[31]}$

Crystal Structure of $\left[\mathbf{E u}\left(\mathrm{NO}_{3}\right)_{3}\left(\mathbf{L}^{11}\right)(\mathrm{MeCN})\right]$ : The block-shaped crystals were directly transferred from the mother liquor into a drop of Hostinert 216 and kept at $210 \mathrm{~K}$. A specimen was selected and placed in a glass capillary. The data collection took place at $150 \mathrm{~K}$ on a Stoe IPDS system equipped with Mo- $K_{\alpha}$ radiation. The detector-crystal distance was set to $80 \mathrm{~mm}$, and a $\varphi$ interval of $1^{\circ}$ was chosen. Two hundred images were collected with an exposure time of $10 \mathrm{~min} / \mathrm{image}$. The integration was based on an effective mosaic spread of 0.011 and a profile of between 9 and 21 pixels. The intensities were corrected for Lorentz and polarisation effects. No absorption correction could be applied since the crystal was all but invisible in the frozen oil, but the absorption coefficient appears to be small. The decay during the measurement was negligible. The structure was solved and refined on $F^{2}$ with the help of the SHELX system. ${ }^{[32]}$ In the final model, a part of the ligand was described with isotropic atomic displacement parameters and all atoms in $\mathbf{L}^{\mathbf{1 1}}$ were submitted to rigid link restraints. All hydrogen atoms were clearly visible in the difference electron density maps, and were included in a riding atom model. The last cycles continued to show a non-zero maximal parameter chance over $\sigma$. This is due to the fact that the Flack parameter ${ }^{[33]}$ (refined as a component in the least-squares) turns negative at the end of each of the final cycles; it is then reset to zero by the program. The structure was analysed using SHELXTL 5.05 ${ }^{[34]}$ and PLATON. ${ }^{[35]}$ The refinement favours the $S$ configuration for the chirality centres $\mathrm{C} 21$ and $\mathrm{C} 23$, as expected from the synthesis.

Crystal Data: $\mathrm{C}_{31} \mathrm{H}_{36} \mathrm{EuN}_{9} \mathrm{O}_{9}, M=830.65$, monoclinic, space group $P 2_{1}\left(\mathrm{~N}_{0} 4\right), a=10.172(2), b=16.804(3), c=10.989(2) \AA$, $U=1697.2(6) \AA^{3}, T=150(2) \mathrm{K}, Z=2, \mu\left(\mathrm{Mo}-K_{\alpha}\right)=1.915 \mathrm{~mm}^{-1}$, 10740 reflections measured, 5205 unique $\left(R_{\text {int }}=0.1013\right)$ which were used in all calculations. The final $w R\left(F^{2}\right)$ was 0.0347 (all data). CCDC-217485 contains the supplementary crystallographic data for this paper. These data can be obtained free of charge at www.ccdc.cam.ac.uk/conts/retrieving.html [or from the Cambridge Crystallographic Data Centre, 12, Union Road, Cambridge CB2 1EZ, UK; Fax: (internat.) + 44-1223/336-033; E-mail: deposit@ccdc.cam.ac.uk]. 
Preparation of the 1:1 Nitrato Complexes: The 1:1 complexes $\left[\mathrm{Ln}\left(\mathrm{NO}_{3}\right)_{3}\left(\mathbf{L}^{\mathbf{1 1}}\right)(\mathrm{MeCN})_{x}\right][x=0, \mathrm{La} \mathrm{(1)}, \mathrm{Gd}(\mathbf{3}), \mathrm{Tb}(\mathbf{4}) ; x=1, \mathrm{Eu}$ (2)] were prepared by mixing equivalent amounts of $\mathrm{Ln}\left(\mathrm{NO}_{3}\right)_{3} \cdot n \mathrm{H}_{2} \mathrm{O}(\mathrm{Ln}=\mathrm{La}, \mathrm{Eu}, \mathrm{Gd}, \mathrm{Tb}$ and $n=5-6)$ and $\mathbf{L}^{\mathbf{1 1}}$ in dichloromethane/acetonitrile $(1: 4 \mathrm{v} / \mathrm{v})$ and the residual suspension was refluxed for $30 \mathrm{~min}$. The complexes were crystallised in $70-80 \%$ yield by slow evaporation of the solvent and were characterised by their IR spectra (Table S1) and elemental analyses. $\left[\mathrm{C}_{29} \mathrm{H}_{33} \mathrm{LaN}_{8} \mathrm{O}_{9}\right.$ (776.53): calcd. C 44.9, $\mathrm{H} \mathrm{4.3,} \mathrm{N} \mathrm{14.4;} \mathrm{found} \mathrm{C}$ 44.9, $\mathrm{H} 4.3, \mathrm{~N}$ 14.3. $\mathrm{C}_{31} \mathrm{H}_{36} \mathrm{EuN}_{9} \mathrm{O}_{9}$ (830.64): calcd. $\mathrm{C} 44.8, \mathrm{H} 4.4$, $\mathrm{N} 15.2$; found $\mathrm{C} 44.6, \mathrm{H} \mathrm{4.3,} \mathrm{N}$ 15.0. $\mathrm{C}_{29} \mathrm{H}_{33} \mathrm{GdN}_{8} \mathrm{O}_{9}$ (794.88): calcd. $\mathrm{C}$ 43.8, $\mathrm{H}$ 4.2, $\mathrm{N}$ 14.1; found $\mathrm{C} 43.9, \mathrm{H}$ 4.3, $\mathrm{N} 14.1$. $\mathrm{C}_{29} \mathrm{H}_{33} \mathrm{~N}_{8} \mathrm{O}_{9} \mathrm{~Tb}$ (796.55): calcd. $\mathrm{C} 43.7, \mathrm{H} \mathrm{4.2,} \mathrm{N} \mathrm{14.1;} \mathrm{found} \mathrm{C}$ 43.7, H 4.1, N 14.1].

\section{Acknowledgments}

This work is supported through grants from the Swiss National Science Foundation. HB thanks the Danish Training Council for additional funding. We thank Prof. Pierre Vogel for the use of his polarimeter.

[1] J.-C. G. Bünzli, Spectroscopic Properties of Rare Earths in Optical Materials (Eds.: G. K. Liu and B. Jacquier), Springer Verlag, Berlin, 2003, Ch. 11, in press.

[2] D. Parker, Coord. Chem. Rev. 2000, 205, 109-130.

[3] J.-C. G. Bünzli, in Metal Ions in Biological Systems (Eds.: A. Sigel and H. Sigel), Marcel Dekker Inc., New York, 2003, Vol. 42, Ch. 2, in press.

[4] V. W. W. Yam, K. K. W. Lo, Coord. Chem. Rev. 1998, 184, $157-240$.

[5] G. Bobba, R. S. Dickins, S. D. Kean, C. E. Mathieu, D. Parker, R. D. Peacock, G. Siligardi, M. J. Smith, J. A. G. Williams, C. F. G. C. Geraldes, J. Chem. Soc., Perkin Trans. 2 2001, $1729-1737$.

${ }^{[6]}$ H. Tsukube, S. Shinoda, Chem. Rev. 2002, 102, 2389-2403.

[7] D. Parker, R. S. Dickins, H. Puschmann, C. Crossland, J. A. K. Howard, Chem. Rev. 2002, 102, 1977-2010.

[8] G. Muller, J.-C. G. Bünzli, J. P. Riehl, D. Suhr, A. von Zelewsky, H.-R. Mürner, Chem. Commun. 2002, 1522-1523.

[9] G. Muller, B. Schmidt, J. Jiricek, G. Hopfgartner, J. P. Riehl, J.-C. G. Bünzli, C. Piguet, J. Chem. Soc., Dalton Trans. 2001, 2655-2662.

${ }^{[10]}$ G. Muller, J. P. Riehl, K. J. Schenk, G. Hopfgartner, C. Piguet, J.-C. G. Bünzli, Eur. J. Inorg. Chem. 2002, 3101-3110.
${ }^{[11]}$ G. Muller, J.-C. G. Bünzli, K. J. Schenk, C. Piguet, G. Hopfgartner, Inorg. Chem. 2001, 40, 2642-2651.

${ }^{[12]}$ K. Nakamoto, Infrared and Raman Spectra of Inorganic and Coordination Compounds. Part A. Theory and Applications in Inorganic Chemistry, Wiley Interscience, New York, 1997.

${ }^{[13]}$ C. Piguet, A. F. Williams, G. Bernardinelli, E. Moret, J.-C. G. Bünzli, Helv. Chim. Acta 1992, 75, 1697-1717.

${ }^{[14]}$ S. Petoud, J.-C. G. Bünzli, K. J. Schenk, C. Piguet, Inorg. Chem. 1997, 36, 1345-1353.

${ }^{[15]}$ H. Jingyu, S. Qi, J. Zhongsheng, Kexue Tongbao (Chin. Sci. Bull.) 1990, 35, 1090-1092.

${ }^{[16]}$ W. Shuangxi, Z. Ying, C. Yuxin, W. Liufang, L. Qinhui, J. Chem. Soc., Dalton Trans. 1994, 2523-2530.

${ }^{[17]}$ R. D. Shannon, Acta Crystallogr., Sect. A 1976, 32, 751-767.

${ }^{[18]}$ E. R. Malinowski and D. G. Howery, Factor Analysis in Chemistry, John Wiley, New York, Chichester, Brisbane, Toronto, 1980.

[19] S. Petoud, J.-C. G. Bünzli, T. Glanzman, C. Piguet, Q. Xiang, R. P. Thummel, J. Lumin. 1999, 82, 69-79.

${ }^{[20]}$ C. Piguet, J.-C. G. Bünzli, G. Bernardinelli, C. G. Bochet, P. Froidevaux, J. Chem. Soc., Dalton Trans. 1995, 83-97.

${ }^{[21]}$ F. J. Steemers, W. Verboom, D. N. Reinhoudt, E. B. van der Tol, J. W. Verhoeven, J. Am. Chem. Soc. 1995, 117, 9408-9414.

[22] S. Tobita, M. Arakawa, I. Tanaka, J. Phys. Chem. 1984, 88, 2697-2702. S. Tobita, M. Arakawa, I. Tanaka, J. Phys. Chem. 1985, 89, 5649-5654.

${ }^{[23]}$ M. H. V. Wertz, R. T. F. Jukes, J. W. Verhoeven, Phys. Chem. Chem. Phys. 2002, 4, 1542-1548.

${ }^{[24]}$ F. R. Gonçalves e Silva, R. Longo, O. L. Malta, C. Piguet, J.C. G. Bünzli, Phys. Chem. Chem. Phys. 2000, 2, 5400-5403.

${ }^{[25]}$ G. Muller, PhD. Dissertation, University of Lausanne, 2000.

[26] J. P. Riehl, F. S. Richardson, Chem. Rev. 1986, 86, 1-16.

[27] J.-C. G. Bünzli, J.-R. Yersin, C. Mabillard, Inorg. Chem. 1982, $21,1471-1476$.

${ }^{[28]}$ W. C. Wolsey, J. Chem. Educ. 1973, 50, A335-A337.

${ }^{[29]}$ R. Rodríguez-Cortiñas, F. Avecilla, C. Platas-Iglesias, D. Imbert, J.-C. G. Bünzli, A. de Blas, T. Rodríguez-Blas, Inorg. Chem. 2002, 41, 5336-5349.

[30] S. R. Meech, D. C. Phillips, J. Photochem. 1983, 23, 193-217.

${ }^{[31]}$ H. Gampp, M. Maeder, C. J. Meyer, A. D. Zuberbühler, Talanta 1985, 23, 1133-1139.

${ }^{[32]}$ G. M. Sheldrick, Acta Crystallogr., Sect. A 1997, 46, 467-473.

${ }^{[33]}$ H. D. Flack, Acta Crystallogr., Sect. A 1983, 39, 876-881.

${ }^{[34]}$ G. M. Sheldrick, SHELXTL 5.05 Siemens Analytical X-ray Instruments Inc., Madison, WI, 1996.

${ }^{[35]}$ A. L. Spek, Acta Crystallogr., Sect. A 1990, 46, C34.

Received June 26, 2003 Early View Article

Published Online October 2, 2003 